\title{
From Kafka to Casualty: doctors and medicine in popular culture and the arts- a special studies module
}

Brian Glasser Royal Free \& University College Medical School, London

Contributing authors: Michael Clark, Trisha Greenhalgh, Christine Harmar-Brown, Joan Leach, Michael Modell, John Salinsky

\begin{abstract}
This paper describes and reflects on the content and teaching methods of a two-week medical humanities special studies module (SSM) taken by third-year students at the Royal Free E University College Medical School. It aims to add to the common pool of knowledge, and will be of use to people who are considering setting up something similar. (F Med Ethics: Medical Humanities 2001;27:99-101)
\end{abstract}

Keywords: Undergraduate medical humanities education; professional identity; popular culture; the arts; film; theatre

\section{Background}

Tomorrow's Doctors ${ }^{1}$ emphasised the need to develop the cultural sensitivities, imagination and interpretive skills of trainee doctors, thereby creating a climate in which medical humanities courses could be accepted into mainstream undergraduate medical education. In 2001, for the third consecutive year, the Centre for Medical Humanities at the Royal Free \& University College Medical School ran a special study module (SSM) for third-year undergraduates entitled "From Kafka to Casualty: doctors and medicine in popular culture and the arts". In total, 28 students have now taken part in this two-week full-time course. The SSM has consistently been one of the most heavily subscribed in the school (numbers are limited to ten a year) and, in line with one of the central tenets of Tomorrow's Doctors, all those that have taken part in the course have chosen to do so.

The originator of the course (BG) has an academic background in comparative literature and medical sociology with experience in medical humanities teaching, ${ }^{2}$ and is supported by a team of medical and non-medical tutors. Individual tutors have been responsible for designing the shape and content of their own day, in discussion with the course organiser. This policy of allowing the module to be shaped by tutors' enthusiasms filtered through the organiser's overview has been fundamental.

\section{Course aims}

The course has two main aims:
(1) To encourage students to think about themselves as embryonic doctors: how will others see them, and how will they see themselves? That is, it tries to promote an understanding of professional identity.

(2) To help students develop their analytic and interpretive skills. Students work to appreciate the range of (and frequent disparity between) professional self images and lay views of doctors and medicine, and the extent to which lay expectations and beliefs about medical practice are influenced by the arts and popular culture.

\section{Course content and delivery}

The teaching combines small-group work with guided private study. A number of specific sessions are outlined below. Comments about the sessions from the tutor perspective follow.

Day One-introductory session: This includes an informal lecture about the "epidemiology" of artistic representations of doctors, and an introduction to textual analysis in the arts.

Day Two-"Doctors in the movies: saints and sinners, and points in between": An introductory review using photo stills outlines the range of portrayals of doctors in films. The various attempts that have been made to map the genre are explained..$^{3-5}$ A practical exercise follows: a shot-byshot analysis of a 3- to 5-minute sequence in three feature films on video. The sequences prime discussions about representations of doctors as scientific pioneers (Dr Ehrlich's Magic Bullet, Warner Bros, 1940); heartless technicians (The Doctor, Touchstone Pictures, 1991), and humanitarian idealists (Awakenings, Columbia Pictures, 1990). Students also watch and discuss longer film extracts (about 15 minutes) on broader themes linking medicine to wider social and political issues, such as doctors and politics (Dr Zhivago, MGM, 1965); doctors breaking rules (The Citadel, MGM, 1938), and doctors over-reaching themselves (Extreme Measures, Simian Films, 1996).

Day Three-"Franz Kafka and the out-of-hours home visit" (using the short story The Country Doctor $^{6}:$ The students are divided into three subgroups, each with a task on which they must report back. Subgroup one plot the course of the story, think 
about what it means and discuss their responses. Subgroup two think about what the story has to say to doctors (there is plenty of material about demanding patients, angry doctors, a fatal diagnosis and professional "burnout"). Subgroup three are given a comic strip biography of Kafka to present. ${ }^{7}$

Day Four-"Doctors on the box: Casualty": Students find out about the mechanics of, and principles behind, the production of the BBC $1 \mathrm{TV}$ soap, Casualty. In the process, they watch and discuss an episode of Casualty, study a first draft of a resuscitation scene, make suggestions to increase authenticity, and then compare their response with the final result. They then develop a scenario and write a scene portraying medical staff at work. The day is underpinned by the inquiry into the concept of illness as drama and the accuracy/inaccuracy of representations of doctors and the health service in a popular TV series.

Day Five-"Ethics, equity and evidence-based medicine: The Doctor's Dilemma": Students listen to a recording of the first act of the BBC Radio 3 production (May 1999) of Bernard Shaw's play, and tackle the subsequent acts as a play-reading. Subgroups then discuss the three topics listed in the session's title. They report back to the full group, which then considers the play's relevance one hundred years after it was written. ${ }^{8}$

Day Six-"Health professionals across a cultural divide": Using short stories, ${ }^{9}$ case histories and background sociological material, ${ }^{10}$ students consider how patients and doctors may perceive each other when they come from different cultures, and the effect of this on clinical practice.

Day Seven-"Medicine in the news: Doctors at times of health scares": Students examine newspaper cuttings and analyse the ways in which doctors represent risk, portray themselves as trustworthy and construct themselves as experts. In addition they look at the representation of medical expertise in non-fiction contexts such as television news and documentary. This prepares students to try their hand at being experts themselves: in a TV studio, students interview each other "to camera", and edit and produce a short discussion programme on a current medical issue.

Day Eight-"Inequalities in doctors and their patients": At the outset of the module, students are each given a copy of the novel, Captain Corelli's Mandolin to read. ${ }^{11}$ They are asked to prepare certain themes for discussion-for instance, the most appropriate methods of training future doctors, the limitations of medicine in the days before modern drugs, and whether an honest, but very blunt approach can be in the patient's best interest.

\section{Reflections}

This course aims to introduce students to bodies of knowledge of which they are likely to have been unaware without making said bodies daunting; and to convince them of the credibility and importance of medical humanities. A concomitant objective is to establish a good dynamic within the group, and create an enjoyable atmosphere in which students feel comfortable expressing themselves as they make some modest inroads into the discipline.

The students take to the filmic "dissection" easily, and enjoy the hands-on nature of their task but find the macro level of sociopolitical analysis more difficult. The session on crosscultural difficulties also proves challenging. There can be some resistance on the part of students to living through the experiences of both health professionals and patients who are socially or culturally distant from themselves. However, using a range of methods, including reflection on published literature and art, personal stories and role-play, they gradually engage with the themes.

The analysis of Casualty from a professional perspective and the consideration of the moral and ethical responsibility of television portrayals of incidents such as suicide, is well received. Despite initial misgivings about writing their own scenes, this exercise provides a stimulating way for students to explore the significance of good communication between doctor and patient.

Students are frequently critical of what they see as the negative impact of the news media; but it is important for them to recognise that medical expertise is constructed in non-fiction contexts as well as in fictional contexts. By giving them a chance both to analyse and to produce their own media texts, students gain an appreciation for news values and the role of expertise in contemporary "health scares".

The students have few difficulties working with literature (here, work by Kafka, Shaw and de Bernières). They are generally intrigued by the way the artist's life and work illuminate each other in the case of Kafka; astonished at how timeless is Shaw's play; and perplexed at how seemingly decent human beings can come to commit monstrous deeds (in de Bernières's novel). The key to success in these sessions is to insist on preparatory reading as well as on "classroom" participation.

\section{Assessment}

The course is not examinable, so any formal assessment of students is more usefully formative than summative. Different methods have been used, such as a short piece of creative writing where students are paired up and asked to write about the same medical incident from two different points of view (for instance those of patient and doctor); or the writing of a 500-word review for a broadsheet or student newspaper about one of the books or films they have encountered on the course. More informally-but no less importantly-tutor feedback about student effort and achievement is phoned in at the end of each day to the course organiser.

\section{Evaluation}

The course has received consistently positive evaluation. Tutors enjoy teaching on it, and none has yet exercised their annual right to opt out of 
contributing. The medical school has asked if the course can be offered more frequently, and has used it to advertise the special study module programme to second-year students. It is important to note that the course's success relies as much on the traditional educational pillars of planning and teaching skills as on its content; and it benefits immeasurably from having two uninterrupted weeks of the students' timetable dedicated to it

\section{Closing thoughts}

This module targets the nature of students' awareness, and their ability to interpret their own experience and that of their patients in humane as well as purely medical or scientific ways. By giving the students a structured "holiday" from the reductionis nature of much of their medical degree (a passing observation they themselves make frequently), they are able to appreciate important aspects of both doctors' and patients' experiences for which no adequate medical terms exist.

Brian Glasser, BA (Hons), MSc, is Honorary Lecturer in the Centre for Medical Humanities, Department of Primary Care \& Population Sciences, Royal Free E University College Medical School, London. Dr Michael Clark, Medical Film E Video Library, Wellcome Trust; Christine Harmar-Brown, freelance writer and tutor; Professor Trish Greenhalgh, Royal Free \& University College Medical School; Dr foan
Leach, Imperial College; Professor Michael Modell, Royal Free $\mathcal{E}$ University College Medical School, and Dr fohn Salinsky, General Practitioner and GP course organiser.

\section{References}

1 General Medical Council. Tomorrow's doctors-recommendations on undergraduate medical education. London: General Medical Council, 1993

2 Glasser B. Literature and medicine. Education for General Practice 1999;10:209-14

3 Shortland M. Medicine and film: a checklist, survey and research resource. Oxford: Wellcome Unit for the History of Medicine, 1989.

4 Jouhaneau J. Les scientifiques vus par les cinéastes. In: Martinet A, ed. Le cinéma et la science. Paris: CNRS Editions, 1994.

5 Dans P. Doctors in the movies: boil the water and just say aaah. Bloomington IL: Medi-Ed Press, 2000.

6 Kafka F. (1919) A country doctor [translated by Muir W and E]. In: Glatzer N N, ed. Penguin complete short stories of Franz Kafka. London: Penguin, 1983. For a discussion of this story, safka. London: Penguin, 1983. For a discussion of this story, infected by suspicion. fournal of Medical Ethics: Medical infected by suspicion.

7 Humanities 2000;26:85-91. 7 Mairowitz DZ

8 Shaw GB. The doctor's dilemma. London: Penguin, 1906.

9 Campo R. Fifteen minutes after Gary died. The desire to heal. Boston: WW Norton \& Company, 1997.

10 Morgan $M$. The meaning of high blood pressure among AfroCaribbean and white patients. In: Kelleher D, Hillier S, eds. Researching cultural differences in health care. London: Routledge, 1996.

11 De Bernières L. Captain Corelli's mandolin. London: Vintage, 1994. 